\title{
Periferik İntravenöz Katetere Bağlı Flebit Oranının ve Etkileyen Faktörlerin Değerlendirilmesi
}

\author{
Soner BERSE *, Betül TOSUN **, Nuran TOSUN ***
}

Öz

Giriș: Periferik venöz kateterler doğru șekilde uygulandığında yaşamsal önemi olan bir araç olduğu kadar; birçok faktör sebebiyle hastada flebite neden olabilmektedir. Amaç: Bir iç hastalıkları kliniğinde periferik intravenöz kateter ilişkili flebit insidansını ve etkileyen risk faktörlerini belirlemektir. Yöntem: Tanımlayıcı, kesitsel tipte planlanan bu çalışmada, 26 Aralık 2018-30 Mart 2019 tarihleri arasında bir iç hastalıkları kliniğinde 93 hastaya uygulanan 195 periferik intravenöz kateter araştırmanın örneklemini oluşturdu. Veriler "Hasta Bilgi Formu" ve Uluslararası İntravenöz Hemşireler Birliği tarafından kullanılması önerilen "Flebit Tanılama Skalası" ile toplandı. Kategorik değişkenlerin karşılaştırılmasında ki-kare testi, risk faktörlerinin değerlendirilmesinde Lojistik regresyon analizi kullanıldı. Bulgular: Hastaların \%50.5'i erkek, yaş ortalaması $56.86 \pm 18.031$ yıldı. Flebit değerlendirme skalasına göre hastaların \%28.2'sinde $(\mathrm{n}=55)$ flebit semptomları saptandı. Yaş grubu 66-90 arasında olan $(\mathrm{p}=.015)$, kronik hastalığı olan $(\mathrm{p}=.005)$, hastanın aktif olarak kullanmadığı tarafa intravenöz kateterizasyon takılan $(\mathrm{p}=.012)$, intravenöz infüzyonu devam eden $(\mathrm{p}=.007)$, aynı damara kateterizasyon sıklığı birden fazla olan $(\mathrm{p}<.001)$, daha önce aynı damar boyunca kateter takılmış olan $(\mathrm{p}=.001)$. ve takılma süresi 72-96 saat olan $(\mathrm{p}=.045)$ hastalarda flebit semptomları görülme sıklı̆̆ı daha fazlaydı. Sonuç: Bu çalışmada periferik intravenöz kateterlerin dörtte birinden daha fazlasında flebit olduğu, ileri yaşın, kronik hastalığın, sürekli infüzyonun, aynı damara birden fazla kateterizasyonun ve kateterin kalış süresinin uzun olmasının hastalarda flebitin görülme oranını artırdığı bulundu. Hemşirelerin flebit gelişimi açısından belirtilen risk faktörlerini kateter uygulaması ve bakımı konusunda göz önünde bulundurmaları, uygulanan periferik intravenöz kateterlerin geçerli ve güvenilir ölçüm araçları ile düzenli olarak flebit belirtileri açısından değerlendirilmesi önerilmektedir.

Anahtar Kelimeler: Periferik İntravenöz Kateter, Flebit, İnsidans, Hemşirelik.

\section{Abstract}

\section{Assessment of Incidence of Phlebitis Associated with Peripheric Intravenous Catheter and Affecting Factors}

Background: Peripheral venous catheters which are vital tools when applied correctly and effectively, can cause phlebitis due to many factors. Objectives: To assess the incidence of phlebitis associated with peripheric intravenous catheter and affecting factors in an internal medicine clinic. Methods: This descriptive, cross-sectional study was conducted in December 2018-March 2019 in the internal medicine clinic. The sample consisted of 195 peripheric intravenous catheters on 93 patients. Data was collected by "Patient Information Form" and "Phlebitis Diagnosis Scale". Chi-square test was used to analyze discrete variable and risk factors were determined by using Logistic Regression analyses. Results: Mean age of the participants was $56.86 \pm 18.031$ years and $50.5 \%$ of them were male. According to the Phlebitis Diagnosis Scale, phlebitis symptoms were observed in $28.2 \%(\mathrm{n}=55)$ of the 195 peripheric catheters. Phlebitis incidence was higher in patients aged 66-90 years old $(\mathrm{p}=.015)$, patients who had chronic diseases $(\mathrm{p}=.005)$, patients who had continuous intravenous infusion $(\mathrm{p}=.007)$, patients who were catheterized for 72-96 hours $(\mathrm{p}=.045)$, catheters placed on the inactive upper extremity of the patient $(p=.012)$, catheters which were not placed successfully in the first attempt $(p=.001)$, catheters which were placed on a vein which was previously catheterized $(\mathrm{p}=.001)$. Conclusion: Phlebitis symptoms were seen in more than one quarter of the patients. Phlebitis incidence was increased in elderly patients with chronic diseases and patients having continuous intravenous infusion, repetitive catheterization in the same vein and prolonged catheterization time. It is recommended for nurses to keep in mind the risk factors for phlebitis development during catheter application and care and to assess the patients with peripheric intravenous catheter regularly with valid and reliable tools and to conduct studies on minimizing the phlebitis development risk.

Keywords: Peripheric Intravenous Catheter, Phlebitis, Incidence, Nursing.

\section{Geliş tarihi: 15.08.2019 Kabul tarihi: 19.06.2020}

$\mathrm{T}$

edavi sürecinin vazgeçilmez uygulamalarından biri olan ve henüz yerine alternatif bir yöntem kullanılmayan periferik intravenöz kateterler (PİK); ilaç tedavisinin uygulanması, total parenteral beslenmenin sağlanması, hemodinamik izlemin yapılması, sıvı elektrolit kaybının önlenmesi, kan ve kan ürünlerinin transfüzyonu ve tanıya yardımcı bazı uygulamalar nedeniyle sıklıkla uygulanmaktadır (1). PİK'ler doğru ve etkili şekilde uygulandığında yaşamsal önemi olan bir araç olduğu kadar; hasta kaynaklı faktörler ve hatalı uygulamalar sebebiyle birçok komplikasyona neden olabilmektedir. Bu komplikasyonlar sıklıkla infiltrasyon, doku hasarı, ağrı ve flebit olarak sıralanabilir. Bu belirti ve bulgular PİK uygulaması sırasında görülebileceği gibi, kateter çıkarıldıktan 24-96 saat sonra da gelişebilmektedir $(2,3)$. Flebit venin intima tabakasındaki inflamasyon durumudur ve doku hasarına yanıt olarak gelişir. Hastada ağrı, eritem, kızarıklık, ödem ve damarda sertleşme ile karakterizedir (4). Literatürde PíK kaynaklı flebit insidansının \%1.25-\%80 arasında geniş bir aralıkta değiştiği bildirilmektedir (5-8). PİK ilişkili flebit gelişimi halen klinik uygulamada önemli bir sorun olarak görülmeye devam edilmekte (9) ve birçok ülkenin verilerinin kullanıldı̆̆ı, son dönemde yapılan çok merkezli bir çalışmada flebit gelişiminin hala global ve yaygın bir sorun olduğunu belirtilmektedir (10). Periferik intravenöz kateter kaynaklı flebitin yaş, cinsiyet, mevcut kronik hastalıklar (diyabet, kalp hastalı̆̆ı, kronik obstrüktif akciğer hastalığı (KOAH), vb.) gibi hasta kaynaklı faktörlerden etkilendiği belirtilmektedir $(1,8,11)$. İlaveten PİK’ten uygulanan ilaçların kimyasal bileșenleri, dozu, osmolaritesi, PİK uygulaması sırasında kullanılan kateter tipi/büyüklüğü ve kalış süresinin flebit gelişimini etkilediğini bildiren çalışmalar bulunmaktadır $(8$, $11,12)$.

* Uzm. Hem., Ersin Aslan Eğitim ve Araştırma Hastanesi, Gaziantep. E-mail: soner.berse@ gmail.com, ORCID: 0000-0001-9108-3216 ** Dr. Öğretim Üyesi Hasan Kalyoncu Üniversitesi, Sağlık Bilimleri Fakültesi, Hemșirelik Bölümü, Gaziantep. E-mail: tosunbetul@ gmail.com, ORCID: 0000-0002-4505-5887 ***Dr. Öğretim Üyesi Hasan Kalyoncu Üniversitesi, Sağlık Bilimleri Fakültesi, Hemşirelik Bölümü, Gaziantep. E-mail: nuran.tosun@hku.edu.tr, ORCID: $0000-0002-8414-8269$ 
PİK ilişkili flebit gelişimi hem hastayı hem de sağlık sistemini olumsuz yönde etkilemektedir. Hasta gelişen flebit kaynaklı ağrı, anksiyete, stres yaşayabilir ve tedavisi yarım kalabilir. Bu durum aynı zamanda hastanede kalış süresinin uzamasına neden olan bakteriyemi, tromboflebit gelişiminin yanı sıra sağlık harcamalarında da artışa neden olabilmektedir (4). Son yirmi yılda PIK ilişkili flebite etki eden faktörleri inceleyen birçok çalışma $(1,3,5-8,11)$ olmakla birlikte literatürde flebit oluşumunu etkileyen risk faktörleri klinik uygulamada tartışmalı bir konudur. Hemşireler düşme riski, basınç ülseri ve ağrı değerlendirmesi hemşirelik uygulamalarını ve hastanın sağlığını etkiyen birçok faktörü rutin olarak değerlendirirken flebit değerlendirilmesini düzenli bir şekilde yapmamakta ve flebiti oluşturan risk faktörleri tam olarak bilinmemektedir (13). İlaveten özellikle yaşam süresinin uzaması ile birlikte kronik hastalıkları ile yaşayan yaşlı hasta popülasyonunun arttığı ve bu hastaların iç hastalıkları kliniklerinde yatarak tedavi gördükleri göz önünde bulundurulduğunda, bu konuda yapılan çalışmaların PİK ilişkili flebit gelişiminin oranını ve etkileyen risk faktörlerini ortaya koyarak bu konuda geliştirilecek kanıta dayalı hemşirelik uygulamalarına rehberlik edeceği düşünülmektedir. Bu bilgiler 1şığında çalışmamız hastada PİK ilişkili flebitten korunması için risk faktörlerinin ve araştırmanın yapıldığı iç hastalıkları kliniğinde PİK ilişkili flebit insidansını belirlemek amaciyla planlandi.

Tanımlayıcı tipte bir çalışma olması sebebiyle araştırmanın amacına uygun olarak cevaplanması beklenen sorular bulunmaktadir.

- Periferik venöz kateteri olan yatan hastalarda flebit durumu ve derecesi nedir?

- Periferik venöz kateteri olan yatan hastalarda flebit oluşumunu etkileyen faktörler nelerdir?

\author{
Araştırmanın Tipi \\ Yöntem \\ Tanımlayıcı, kesitsel tipte planlanan bu çalışma 26 Aralık 2018 - 30 Mart 2019 tarihleri arasında yapılmıştır. \\ Araştırmanın Yapıldı̆̆ Yer
}

Araştırma Türkiye'nin Güneydoğu Anadolu bölgesinde hizmet veren bir devlet hastanesinin 20 yataklı bir iç hastalıkları kliniğinde yürütüldü. Bu klinikte her vardiyada 4 hemşire çalışmakta olup genellikle kronik hastalıkları (diyabet, kronik obstrüktif akciğ er hastalığı, astım, hipertansiyon) olan hastalar yatarak tedavi görmektedir.

\title{
Araştırmanın Evreni ve Örneklemi
}

Çalışmanın yapıldığı tarihler arasında 20 yataklı bir devlet hastanesinin iç hastalıkları kliniğinde yatarak tedavi gören 102 hasta çalışmanın evrenini, 18 yaşın üzerinde, Türkçe yazılı ve sözlü iletişim engeli olmayan ve araştırmaya katılmaya gönüllü olan 93 hasta araştırmanın örneklemini oluşturdu. Araştırmaya katılmayı kabul etmeyen 4 hasta ve yatışı yapıldıktan sonra taburcu olana kadar geçen sürede PİK açılmayan 5 hasta araştırma dışı bırakıldı. Toplam 93 hastaya tedavileri süresince açılan 195 PİK'den toplanan veriler değerlendirilerek araştırma tamamlandı. Bu araştırmada "G. Power-3.1.9.2” programı kullanılarak, \%80 güven düzeyinde örneklem büyüklüğü veri toplama aşamasından önce Uslusoy ve Mete 2008 referans alınarak, uzman bir istatistikçi tarafından hesaplandı. Araştırmada PİK uygulanan hastalarda flebit oluşumunu etkileyen risk faktörlerinin değerlendirilmesi ve istatistiksel analizlerde ki kare analizi yapılması öngörüldü. Buna göre çalışmanın etki büyüklüğü .23; alfa değeri .05 ve teorik güç \%80 alınarak değerlendirilmesi gereken PİK sayısı 207 olarak belirlendi. Araştırma tamamlandıktan sonra yapılan güç analizinde PİK uygulanan hastalarda flebit gelişimini etkileyen risk faktörleri ki kare analizi ile değerlendirildiğinde, etki büyüklüğü .23; alfa değeri .05 olarak yapılan hesaplamada çalışmanın teorik gücü minimum \%70 bulundu. İlaveten istatistiksel olarak anlamlı fark yaratan risk faktörleri değerlendirildiğinde, etki büyüklüğü .40; alfa değeri .05 olarak yapılan hesaplamada çalışmanın teorik gücü maksimum \%94 bulundu. Kateterin takılı olduğu süre boyunca kateter bölgesi günlük olarak aynı araştırmacı tarafından değerlendirildi.

\section{Araştırma Verilerinin Toplanması}

Araştırma verilerinin toplanmasında; 'Hasta bilgi formu', 'Periferik İntravenöz Kateter Değerlendirme Formu' ve 'Flebit Tanılama Skalası' formları kullanıldı. Hastalara PİK uygulanmasını takiben, araştırmaya dahil edilme kriterlerini sağlayan ve araştırmaya katılmaya gönüllü hastalara "Hasta Bilgi Formu" ve "Periferik İntavenöz Kateter Değerlendirme Formu" ile ilk değerlendirme yapıldı. Hastalara uygulanan PİK'ler 4 gün boyunca saat 16:00 ile 18:00 saatleri arasında, düzenli olarak flebit semptomları açısından aynı hemşire tarafından değerlendirildi. Flebit değerlendirme sonucu flebit tespit edilen hastalar sorumlu hemşiresine bildirildi. Flebit gelişen PİK'lerin çıkarılması ve yeniden kateter açılması halinde yeni uygulanan kateter değerlendirmeye alındı.

Periferik intravenöz kateter uygulaması sırasında intravenöz katetere kan gelmemesi, mayi verilememesi, uygulanan bölgede şişme veya ağrı görülmesi ve yeni bir kateter kullanılması veri toplayan araştırmacı hemşire tarafindan başarısız intravenöz girişim olarak değerlendirildi."

\section{Veri Toplama Araçlart}

\section{Hasta Bilgi Formu}

Hastaların sosyo-demografik özelliklerini belirlemek için araştırmacılar tarafından literatürden yararlanılarak hazırlanan hasta bilgi formu; hastaların yaşı, cinsiyeti, mevcut tanısı ve kronik hastalığının var olup olmadığına ilişkin sorulardan oluşmaktaydı $(1,4,8,11)$.

Periferik Intravenöz Kateter Değerlendirilme Formu

Araştırmacılar tarafından literatür taraması $(8,11,14-18)$ sonucunda geliştirilen formda kateter ile ilgili, kateter takılma tarihi, kateter çıkarılma tarihi, kateter girişim bölgesi, kateterin takıldığı vücut bölgesi, hastanın aktif olarak kullandığı vücut tarafı, ilk girişimde başarı durumu, başarısız girişim sayısı aynı damara daha önce girişim yapılıp yapılmadığı, kateter numarası, 
girişim sırasında gelişen komplikasyonlar, kateter çıkarma nedeni, hastanın aldığı intravenöz ilaçlar ve infüzyon sürekliliği ile ilgili sorular yer ald.

Flebit Tanılama Skalası

İntravenöz Hemşireler Birliği $(14,15)$ tarafından geliştirilen skala ile hastalara flebit tanısı koyuldu. Flebitin derecesi araştırmacılar tarafından kullanılan şeffaf milimetrik cetvel ile flebit gelişen alanın genişliği ölçülerek değerlendirildi.

Bu ölçek ile flebit:

Derece 0: semptom yok,

Derece 1: kateter giriş yerinde kızarıklık ve/veya ağrı,

Derece 2: kateter giriş yerinde kızarıklık, ağrı ve/veya ödem,

Derece 3: kateter giriş yerinde kızarıklık, ağrı ve/veya ödem, kırmızı çizgi, venin kablo şeklinde palpe edilmesi,

Derece 4: kateter giriş yerinde kızarıklık, ağrı ve/veya ödem, kırmızı çizgi, venin kablo şeklinde palpe edilmesi ve $2.5 \mathrm{~cm}$ 'den uzun olması, pürülan akıntı şeklinde değerlendirilmektedir $(14,15)$.

\section{Verilerin Değerlendirilmesi}

Çalışmada elde edilen verilerin istatistiksel analizi bilgisayar ortamında Statistical Package for the Social Sciences (SPSS) for Windows 22.0 programında değerlendirildi. Araştırmanın bağımlı değişkeni flebit gelişsimi, bağımsız değişkenleri; yaş, cinsiyet, kronik hastalık varlığı, kateter ve intravenöz tedavi ile ilgili tanımlayıcı özelliklerdir. Verilerin normal dağılıma uygunluğu Shaphiro Wilk Testi ile test edildi. Tanımlayıcı istatistikler sayı, yüzde, normal dağılıma uyan veriler ortalama \pm standart sapma olarak verilmiş olup, hastalara ait yaş, cinsiyet, kronik hastalık varlığı, kateter ve intravenöz tedavi ile ilgili bağımsız değişkenlere göre flebit varlığının karşılaştırılmasında Ki-Kare testi $\left(\mathrm{x}^{2}\right)$ kullanıldı. Üç veya daha fazla grubun karşılaştırılmasında farkın hangi gruptan kaynaklandığı Bonferroni düzeltmesi ile tespit edildi. Bonferoni düzeltmesinden sonra farkın hangi gruptan kaynaklandığının anlaşılır olabilmesi için, üç veya daha fazla grubun karşılaştırıldığı durumlarda istatistiksel olarak anlamlı bulunan fark tabloda $(a-b, c)$ şeklinde gösterildi. Bu gösterimin anlamı; "a" ile işaretlenen değişkenin "b" ve "c" ile işaretlenen değişkenler arasında anlamlı bir fark olduğu, "b" ile "c" arasında kendi içinde istatistiksel olarak anlamlı bir fark olamadığı şeklinde açıklanır. Periferik venöz kateter ilişkili flebit bağımlı değişkenini etkileyen faktörlerin risk hesaplaması lojistik regresyon analizi ile değerlendirildi. Lojistik regresyonda risk faktörleri belirlenirken en uygun model Forward Stepwise (Likelihood Ratio) Metodu kullanılarak değerlendirildi. $\mathrm{p}<.05$ istatistiksel olarak anlaml kabul edildi.

\section{Araştırmanın Etik Yönü}

Araştırmanın uygulamasına başlamadan önce bir üniversitenin sağlık bilimleri enstitüsünden etik kurul izni, (20/11/2018 tarihli ve 2018/29 sayılı karar) ve İl Sağlık Müdürlüğü aracılığı ile çalışmanın yapıldığı hastaneden gerekli izinler (25/12/2018 tarihli ve 76924598-774.99-E.4082 sayılı karar) alındı. Araştırmanın tüm aşamalarında Helsinki bildirgesinde yer alan araştırma ilkeleri ve yayın etiği ilkelerine uyuldu. Araştırmanın yapıldığı tarihler arasında, araştırmanın kabul kriterlerini karşılayan ve araştırmaya katılmaya gönüllü olan hastaların yazılı onamları alındıktan sonra araştırma ile ilgili veriler toplandı.

\section{Bulgular}

Araştırmanın yapıldığı tarihler arasında hastalara $(\mathrm{n}=93)$ uygulanan 195 PİK araştırmaya dahil edildi. PİK açılan hastaların \%50.5'i erkek; yaş ortalaması $56 \pm 18.031$ (min:19 - Maks:90), \%71.0'inin en az bir kronik hastalığ bulunmaktaydı. Kronik hastalardan ilk üç sırada kronik obstrüktif akciğer hastalığı (KOAH) \%33.3 (n = 31), hipertansiyon \%20.4 (n = 19), astım $\% 11.8(\mathrm{n}=11)$ ve diyabetes mellitus \%15.0 ( $\mathrm{n}=14)$ olduğu görüldü (n katlanmıștır) (Tablo 1).

Tablo 1. Hastaların sosyo-demografik ve tanıtıcı özelliklerinin dağılımı (n=93)

\begin{tabular}{|c|c|c|}
\hline Özellikler & $\mathbf{n}$ & $\%$ \\
\hline \multicolumn{3}{|l|}{ Yaş Ort \pm Ss: $56.86 \pm 18.031$ (min:19-maks:90) } \\
\hline \multicolumn{3}{|l|}{ Cinsiyet } \\
\hline Erkek & 47 & 50.5 \\
\hline Kadın & 46 & 49.5 \\
\hline \multicolumn{3}{|l|}{ Kronik Hastalık } \\
\hline Var & 66 & 71.0 \\
\hline Yok & 27 & 29.0 \\
\hline \multicolumn{3}{|l|}{ Kronik Hastalık Varsa* } \\
\hline Kronik Obstrüktif Akciğer Hastalığı & 31 & 33.3 \\
\hline Hipertansiyon & 19 & 20.4 \\
\hline Astim & 11 & 11.8 \\
\hline Diyabetüs Mellitüs & 14 & 15.0 \\
\hline Diğer (Mukopolisakkaridoz (MPS):1 Serebrovasküler Olay Sekeli (SVO):1) & 2 & 2.15 \\
\hline
\end{tabular}


Hastalara açılan PİK'lerde hemşirelerin tamamının üst ekstremiteyi tercih ettiği, en çok kubital alandaki venleri kullandığı $(\% 35.4, \mathrm{n}=69)$, kateterlerin \%50.8'inin $(\mathrm{n}=99)$ hastaların aktif kullandıkları tarafa açıldığı görüldü. İlk girişimde kateter yerleştirme başarı oranı \%74.4 $(\mathrm{n}=145)$ iken, neredeyse kateterlerin tamamına yakınından $\% 0.9 \mathrm{NaCl}$ infüzyonu yapıldığı $(\% 90.8, \mathrm{n}=177)$ ve kateter numaralarına bakıldı̆̆ında yarıya yakınında $(\% 56.9, \mathrm{n}=111) 22 \mathrm{G}$ (mavi kateter) kullanıldığı tespit edildi. Kateterin vende kalma süresi ortalama $44.55 \pm 24.88$ saat iken en çok 72-96 saate kadar takılı kalan kateter sayısının \%3.6 ( $\mathrm{n}=7)$ olduğu gözlemlendi. Hastaların \%28.2'sinde $(\mathrm{n}=55)$ flebit semptomları görülmüş olup, flebit derecesine bakıldığında Derece 1 olan hastalar ile $(\% 20.0, \mathrm{n}=39)$ daha sık karşılaşıldı (Tablo 2).

Tablo 2. Hastalara uygulanan PIK ve tedavi ile ilişkili faktörlerin dağılımı (n=195)

\begin{tabular}{|c|c|c|}
\hline Özellikler & Sayı (n) & $\%$ \\
\hline \multicolumn{3}{|l|}{ PİK açılan vücut tarafi } \\
\hline Aktif kullanılan taraf & 99 & 50.8 \\
\hline Aktif kullanılmayan taraf & 96 & 49.2 \\
\hline \multicolumn{3}{|l|}{ Girişim bölgesi } \\
\hline Kubital ven & 69 & 35.4 \\
\hline Sefalik ven & 48 & 24.6 \\
\hline Dorsal metakarpal & 45 & 23.1 \\
\hline Basilik ven & 33 & 16.9 \\
\hline \multicolumn{3}{|l|}{ İlk girişimde başarı oranı } \\
\hline Evet & 145 & 74.4 \\
\hline Hayır & 50 & 25.6 \\
\hline \multicolumn{3}{|c|}{ PİK'ten verilen Intravenöz sıvılar } \\
\hline$\% 0.9 \mathrm{NaCl}$ & 177 & 90.8 \\
\hline$\% 5$ Dekstroz & 14 & 7.2 \\
\hline Isolayt $\mathrm{S}$ & 2 & 1.0 \\
\hline Diğer & 2 & 1.0 \\
\hline \multicolumn{3}{|l|}{ IV infüzyon sürekli mi? } \\
\hline Evet & 137 & 70.3 \\
\hline Hayır & 58 & 29.7 \\
\hline \multicolumn{3}{|l|}{ Kateter no } \\
\hline Pembe (20G) & 40 & 20.5 \\
\hline Mavi (22 G) & 111 & 56.9 \\
\hline $\operatorname{Sar} 1(24 G)$ & 44 & 22.6 \\
\hline \multicolumn{3}{|l|}{ Kateter Süresi } \\
\hline$\leq 24$ saat & 73 & 37.4 \\
\hline $25-48$ saat & 77 & 39.5 \\
\hline 49-72saat & 38 & 19.5 \\
\hline 73 -96saat & 7 & 3.6 \\
\hline \multicolumn{3}{|l|}{ Flebit var } \\
\hline Var & 55 & 28.2 \\
\hline Yok & 140 & 71.8 \\
\hline \multicolumn{3}{|l|}{ Flebit derecesi } \\
\hline Derece 0 (yok) & 140 & 71.8 \\
\hline Derece 1 & 39 & 20.0 \\
\hline Derece 2 & 9 & 4.6 \\
\hline Derece 3 & 5 & 2.6 \\
\hline Derece 4 & 2 & 1.0 \\
\hline
\end{tabular}

Araştırmaya katılan hastaların cinsiyetlerine göre flebit oluşumu açısından istatistiksel olarak anlamlı bir fark bulunmazken, yaş gruplarına göre flebit gelişme durumları incelendiğinde 19-40 yaş grubu arasında \%11.1 ( $\mathrm{n}=2$ ), 41-65 yaş aralığında $35.0(\mathrm{n}=14), 66-90$ yaş grubu arasında ise \%51.4 $(\mathrm{n}=18)$ flebit olduğu, yaş ilerledikçe flebit gelişme sıklığının arttığ belirlendi $\left(x^{2}=8.404, p=.015\right)$. Kronik hastalık varlığına göre flebit gelişme durumuna bakıldığında; kronik hastalığ olan bireylerde daha s1k flebit görüldüğü $(\% 45.5, \mathrm{n}=30)$ ve farkın istatistiksel olarak anlamlı olduğu bulundu $\left(\mathrm{x}^{2}=7.756, \mathrm{p}=\right.$ .005). PİK takılan vücut tarafına göre flebit varlığı değerlendirildiğinde hastaların aktif olan tarafina takılan kateterlerde \%20.2 $(\mathrm{n}=20)$, aktif olmayan tarafa takılan kateterlerinde ise \%36.5 $(\mathrm{n}=35)$ flebit geliştiği ve farkın istatistiksel olarak anlamlı olduğu tespit edildi $\left(\mathrm{x}^{2}=6.361, \mathrm{p}=.012\right)$. PİK açılırken ilk denemede başarılı olan kateterde ve kateter takılmak üzere ilk defa kullanılan venlere açılan PİK'lerde istatistiksel olarak anlamlı düzeyde daha az flebit görüldü (sırasıyla; $\mathrm{x}^{2}=18.801, \mathrm{p}<.001$; $\left.\mathrm{x}^{2}=11.682, \mathrm{p}=.001\right)$. 
Çalışmada hastaların neredeyse tamamının intravenöz tedavisi benzerdi. Tüm hastalara antibiotik, mide koruyucu, çeşitli nonsteroid anti-inflamatuvarlar ve neredeyse tamamına \%0.09'luk $\mathrm{NaCl}$ solüsyonu hekimler tarafından istem edilmiştir. Sürekli İnfüzyon uygulamasının flebit gelişimi üzerine etkisine bakıldığında infüzyon devam eden PİK'lerde flebit görülme sıklığının \%83.6 $(\mathrm{n}=46)$ olduğu ve farkın anlamlı düzeyde daha yüksek olduğu bulundu $\left(\mathrm{x}^{2}=6.563, \mathrm{p}=.007\right)$. Çalışmada kateter büyüklüğüne göre flebit varlığı incelendiğinde sarı $(20 \mathrm{G})$ renk kateterlerde \%40.9'unda (n=18) flebit olduğu tespit edildi fakat diğer kateterler ile arasında flebit gelişimi açısından istatistiksel olarak anlamlı bir fark yoktu $\left(\mathrm{x}^{2}=4.529, \mathrm{p}=\right.$ .098) Vende kalma süresi 72-96 saat olan kateterlerlerin \% 71.4'ünde $(\mathrm{n}=5)$ istatistiksel olarak anlamlı düzeyde flebit daha s1k görüldü $\left(\mathrm{x}^{2}=8.031, \mathrm{p}=.045\right)$ (Tablo 3$)$.

Tablo 3. Hastaya ait özellikler ve PİK’e ait bazı faktörlere göre flebit gelişme durumunun karşılaştırılması

\begin{tabular}{|c|c|c|c|c|}
\hline \multirow[b]{2}{*}{ Özellikler } & \multicolumn{2}{|c|}{ Flebit Gelişme Durumu } & \multirow[b]{2}{*}{$\begin{array}{l}\text { Test } \\
\mathbf{X}^{2 *}\end{array}$} & \multirow[b]{2}{*}{$\mathbf{p}$} \\
\hline & $\begin{array}{c}\text { Var } \\
\text { n }(\%)\end{array}$ & $\begin{array}{c}\text { Yok } \\
\text { n(\%) }\end{array}$ & & \\
\hline \multicolumn{5}{|l|}{ Cinsiyet } \\
\hline Kadın & $17(37.0)$ & $29(63.0)$ & \multirow[t]{2}{*}{0.174} & \multirow[t]{2}{*}{.398} \\
\hline Erkek & $17(36.2)$ & $30(63.8)$ & & \\
\hline \multicolumn{5}{|l|}{ Yaş grupları } \\
\hline $19-40(a)$ & $2(11.1)$ & $16(88.9)$ & \multirow{3}{*}{8.404} & \multirow{3}{*}{$\begin{array}{l}.015^{* *} \\
(\mathrm{a}-\mathrm{b}, \mathrm{c})\end{array}$} \\
\hline $41-65(b)$ & $14(35.0)$ & $26(65.0)$ & & \\
\hline $66-90(\mathrm{c})$ & $18(51.4)$ & $17(48.6)$ & & \\
\hline \multicolumn{5}{|l|}{ Kronik Hastalık Varlığı } \\
\hline Var & $30(45.5)$ & $36(54.5)$ & \multirow[t]{2}{*}{7.756} & \multirow[t]{2}{*}{$.005 * *$} \\
\hline Yok & $4(14.8)$ & $23(85.2)$ & & \\
\hline \multicolumn{5}{|c|}{ PIK takılan vücut Tarafı } \\
\hline Aktif olan taraf & $20(20.2)$ & $79(79.8)$ & \multirow{2}{*}{6.361} & \multirow{2}{*}{$.012 * *$} \\
\hline Aktif olmayan taraf & $35(36.5)$ & $61(63.5)$ & & \\
\hline \multicolumn{5}{|c|}{ Ekstremitede girişim bölgesi } \\
\hline Bazilik ven & $10(30.3)$ & $23(69.7)$ & \multirow{4}{*}{1.108} & \multirow{4}{*}{.775} \\
\hline Sefalik ven & $15(31.3)$ & $33(68.8)$ & & \\
\hline Ante-Kübital ven & $20(29.0)$ & $49(71.0)$ & & \\
\hline Dorsol metakarpal ven & $10(22.2)$ & $35(77.8)$ & & \\
\hline \multicolumn{5}{|c|}{ Hemşirenin PİK uygulaması sırasında ilk denemede başarı durumu nedir? } \\
\hline Evet başarılıydı & $29(20.0)$ & $116(80.0)$ & \multirow{2}{*}{18.801} & \multirow{2}{*}{$.001 * *$} \\
\hline Hayır başarısızdı & $26(52.0)$ & $24(48.0)$ & & \\
\hline \multicolumn{5}{|c|}{ Değerlendirilen kateterin aynı damarı boyunca daha önce kateter açılmış mı? } \\
\hline Evet & $13(59.1)$ & $9(40.9)$ & \multirow{2}{*}{11.682} & \multirow{2}{*}{$.001 * *$} \\
\hline Hayır & $42(24.3)$ & $131(75.7)$ & & \\
\hline \multicolumn{5}{|c|}{ İntravenöz infüzyon sürekli mi? } \\
\hline Evet & $46(83.6)$ & $91(65)$ & \multirow{2}{*}{6.563} & \multirow{2}{*}{$.014 * *$} \\
\hline Hayır & $9(16.4)$ & $49(35)$ & & \\
\hline Kateter no & & & & \\
\hline $\operatorname{Sar} 1(24 G)$ & $18(40.9)$ & $26(50.1)$ & & \\
\hline Mavi(22G) & $28(25.2)$ & $83(74.8)$ & & \\
\hline Pembe(20G) & $9(22.5)$ & $31(77.5)$ & 4.529 & .098 \\
\hline Kateterin vende kalm & & & & \\
\hline$\leq 24$ saat $($ a) & $22(30.1)$ & $51(69.9)$ & & \\
\hline 25-48saat (b) & $17(22.1)$ & $60(77.9)$ & & \\
\hline 49-72saat (c) & $11(28.9)$ & $27(71.1)$ & 8.031 & $.045 * *$ \\
\hline $73-96$ saat (d) & $5(71.4)$ & $2(28.6)$ & & $(b-d)$ \\
\hline
\end{tabular}

$*_{\mathrm{x}}^{2}=$ Ki-Kare testi, $* * \mathrm{p}<.05$ istatistiksel olarak anlamlıdır.

PİK ilişkili flebiti etkileyen risk faktörleri lojistik regresyon analizi ile değerlendirildi. Birinci modelde PİK yerleştirilirken ilk girişimde başarılı olmanın flebit riskini 4.364 kat azalttığı (\%95 CI [1.707-11.157], p=.002); ikinci modelde ilk girişimde başarılı olmanın flebit riskini 0.285 kat azalttığ (\% 95CI [0.937-0.992], p=.012), yaşta bir y1l artışın flebit riskini 0.965 kat arttırdığ $1 \% 95$ CI [0.937-0.992], p=.015) üçüncü modelde ise flebit riskini; ilk girişimde başarılı olmanın 0.303 kat azalttığı, yaştaki bir yıllık artışın 0.963 kat arttırdığı ve PİK takılan vücut tarafinın sağ kol olmasının 0.364 kat azalttığ bulundu. (sirasiyla; (\%95 CI [0.110-0.834], p=0.021; \%95 CI [0.934-0.992], p=.014; \%95 CI [0.139-0.956], p=.040).

PIKK ilişkili flebit oluşmasına neden olduğu öngörülen faktörler birlikte değerlendirildiğinde IV infüzyonun devam etmesi ve PİK'in vende kalış süresinin bir saat artmasının flebit riskini 1.026 kat arttırdı̆̆ $(95 \%$ CI [1.005-1.047], p=0.016); 
Araştırma

yaştaki bir yıllık artış ve kronik hastalık varlığının birlikte flebit oluşma riskini 1.033 kat arttırdığ 1 saptandı (\%95 CI [1.0101.056]), $\mathrm{p}=.004)($ Tablo 4).

Tablo 4. Periferik intravenöz kateter ilişkili flebiti etkileyen faktörlere ilişkin lojistik regresyon analizi sonuçları

\begin{tabular}{|c|c|c|c|c|c|c|}
\hline & $\boldsymbol{\beta}$ & SE & Wald & $\mathbf{p}$ & OR & $\% 95 \mathrm{CI}$ \\
\hline \multicolumn{7}{|c|}{ 1. Forward Stepwise (Likelihood Ratio) Metodu } \\
\hline \multicolumn{7}{|c|}{ Model 1 Nagelkerke R-square: 0.138} \\
\hline İlk girişimde başarı durumu (evet) & -1.473 & 0.479 & 9.463 & $.002 *$ & 4.364 & $(1.707-11.157)$ \\
\hline Sabit & 0.301 & 0.239 & 1.583 & .208 & 1.352 & \\
\hline \multicolumn{7}{|l|}{ Model 2 Nagelkerke R-square: 0.223} \\
\hline Yaş (yıl) & -0.036 & 0.015 & 5.928 & $.015^{*}$ & 0.965 & $(0.937-0.992)$ \\
\hline İlk girişimde başarı durumu (evet) & -1.255 & 0.499 & 6.324 & $.012 *$ & 0.285 & $(0.107-0.758)$ \\
\hline Sabit & 2.454 & 0.933 & 6.921 & $.009 *$ & 11.639 & \\
\hline \multicolumn{7}{|l|}{ Model 3 Nagelkerke R-square: 0.275} \\
\hline Yaş (y1l) & -0.038 & 0.016 & 6.010 & $.014^{*}$ & 0.963 & $(0.934-0.992)$ \\
\hline İlk girişimde başarı durumu (evet) & -1.193 & 0.516 & 5.345 & $.021 *$ & 0.303 & $(0.110-0.834)$ \\
\hline PİK takılan vücut tarafı (sağ kol) & -1.010 & 0.493 & 4.207 & $.040 *$ & 0.364 & $(0.139-0.956)$ \\
\hline Sabit & 2.624 & 0.989 & 7.039 & $.008 *$ & 13.790 & \\
\hline
\end{tabular}

\section{Forward Stepwise (Likelihood Ratio) Metodu}

Model 1 Nagelkerke R-square: 0.092

IV İnfüzyon devam ediyor mu? (evet) * Pİ'in vende kalma süresi (saat)

Sabit

Model 2 Nagelkerke R-square: 0.143

Yaş (yıl)*Kronik hastalık varlığı

Sabit

-0.992)

$(0.139-0.956)$

$*=\mathrm{p}<.05$ istatistiksel olarak anlamli; $\mathrm{OR}=$ Odds ratio; $\mathrm{SE}=$ Standart hata; $\% 95 \mathrm{CI}=\% 95$ güven aralığ 1

\section{Tartışma}

Bu araştırmada 93 hastaya uygulanan 195 periferik intravenöz kateter izlenmiş olup flebit gelişimini etkileyen faktörler değerlendirildi. Çalışma kapsamına alınan hastalara uygulanan 195 PİK'in \%28.2'sinde (n=55) flebit geliştiği, PİK'lerin \%20'sinin "Derece 1" flebit olduğu tespit edildi (Tablo2). Yapılan çalışmalar incelendiğinde PİK kaynaklı flebit gelişme oranının farklı çalışmalarda çok geniş aralıklarda (\%1.25-80) belirtildiği görülmüştür (1, 7, 8, 19-21). Braga ve arkadaşları (2018) 110 hasta ile yaptıkları çalışmada flebit gelişme oranını \%43.2 ve flebit derecesi açısından en çok görülen flebit semptomlarını derece 1 olarak belirtirken (19) Urbanetto ve arkadaşları 361 periferik intravenöz kateteri inceledikleri çalışmada yarısından fazlasının derece 1 flebit olmakla birlikte bu oranı \%10 olarak bulmuştur (7). Atay ve arkadaşlarının (2018) yaptığ çalışmada ise PİK'lerin \%31.8'inde flebit geliştiğini ve dörtte üçünün derece 1 flebit olduğunu bildirmiştir (27). PİK ilişkili flebit oranlarının farklılık göstermesinin nedeninin hasta kaynaklı, kateter kaynaklı, tedavi ve bakım kaynaklı birçok faktörden etkilendiğini düşündürmektedir (22). Ayrıca en çok derece 1 flebit semptomlarının görülmesinin nedeni araştırmacıların flebit semptomlarını erken evrede fark edip, flebitin ilerlememesi ile ilgili gerekli önlemleri almasından kaynaklandığı değerlendirilmektedir Periferik intravenöz kateterlerin en az her 8 saatte bir, kritik hastaların, sedatize hastaların ve bilişsel eksiklikleri olan hastaların kateterlerinin ise her 1-2 saatte kontrol edilmesini önermektedir (28). İnfüzyon Hemşireler Birliği PİK kaynaklı flebitin \%5'in altında olmasını kabul edilebilir olarak bildirmiştir (15). Bu çalışmanın ve diğer araştırma sonuçlarının ortaya koyduğu flebit oranları İntravenöz Hemşireler Birliği'nin kabul ettiği flebit oranının oldukça üzerindedir. Yüksek flebit oranlarını daha düşük seviyelere taşımanın, flebit gelişimini etkileyen risk faktörlerini ortaya koymak ve değiştirilebilecek risk faktörleri ile ilgili gerekli önlemlerin alımasıyla mümkün olacağı düşünülmektedir.

$\mathrm{Bu}$ çalışmada cinsiyetler arasında flebit gelişimi açısından bir fark bulunmazken (Tablo 3), bazı çalışmalarda kadın cinsiyette flebit gelişiminin fazla olduğunu gözlemlenmiştir $(25,29)$. Uslusoy ve Mete $(2008)$ ise çalışmamızla benzer şekilde cinsiyetin flebitin gelişiminde bir fark yaratmadığını savunmuştur (8). Bazı çalışmalarda kadın cinsiyette daha fazla flebit oluşumu kadınlardaki damar yapısının erkeklere göre daha ince olması ile açıklanabilir. Bununla birlikte cinsiyetin flebit üzerine etkisi literatürde henüz tartışmalı bir konudur.

İç hastalıkları kliniğinde tedavi gören hastaların yaş ortalamasının 55 yaşın üzerinde olduğu ve 65 yaşın üzerindeki hastalarda daha fazla PİK kaynaklı flebit oluştuğu görüldü (Tablo 3). Simin (2019) yaptığı çalışmada 70 yaş üzeri olanlarda flebit gelişiminin daha fazla olduğunu bildirirken (1) literatürde benzer çalışmalar ileri yaşın flebit gelişimi açısından risk faktörü olduğunu belirtmiştir (22-25). Bu durum yaşlanmanın vücutta oluşan travmalara karşı verdiği immün yanıtın gecikmesi, yaşlanma ile birlikte cilt altı yă̆ dokusunun azalması, hücre yenilenmesinin ve yara iyileşmesinin yavaşlaması ile açıklamak mümkündür $(1,26)$. Araştırmaya katılan hastaların sıklıkla $\mathrm{KOAH}$, diyabet ve hipertansiyon olduğu ve kronik 
hastalık varlığının ve flebit oluşumu üzerine anlamlı düzeyde arttırdı̆̆ı bulundu (Tablo 3). Yapılan birçok çalışmada bu çalışma ile benzer şekilde kronik hastalık varlığı flebit gelişimini etkilediği bulunmuştur (22, 27). İlaveten bu çalışmada yapılan regresyon analizinde yaşın kronik hastalıkla birlikte PİK ilişkili flebit riskini arttırdığı bulundu. İleri yaşta özellikle damar yapısının bozulduğu ve immün sistemin zayıfladığı kronik hastalıkların flebit gelişimini hızlandırdığı ve bu hastaların kateterlerinin daha dikkatli izlenmesi gerektiğini düşündürmektedir.

Araştırmaya katılan hastalarda kateterlerin tamamının üst ekstremiteye uygulandığı bulundu. Anatomik bölgelere göre flebit gelişimi açısından bir fark yokken, vücut tarafı incelendiğinde aktif olmayan tarafa takılan kateter bölgelerinde daha fazla flebit geliştiği bulundu (Tablo 3). Atay ve arkadaşları (2018) iç hastalıkları kliniğinde yaklaşık 500 kateteri inceledikleri çalışmada PİK uygulanan anatomik bölge ve ekstremite tarafının flebit gelişimi üzerine bir etkisi olamadığını belirtirken (27), benzer şekilde Buzatto ve arkadaşları (2016) 102 yaşlı hasta ile yaptıkları çalışmada aktif ve aktif olmayan ekstremiteye uygulanan kateterlerin flebit gelişimi açısından fark oluşturmadığını saptamıştır (30). Bu araştırma sonuçlarının aksine bazı çalışmalarda, hastanın aktif kullandığı tarafta ve eklem yerlerine uygulanan kateterlerin taravmalara daha fazla maruz kalması sebebiyle flebit gelişiminin fazla olacağ değerlendirilmekte, kateterizasyonda hastanın aktif olamayan üst ekstremitelerinde, bölge olarak kübital ven ve ön kol venlerinin kullanılmasının flebit gelişimi riskini azaltacağı bildirilmektedir (8, 17, 26). Bu çalışmada hastaların aktif olmayan tarafında daha fazla flebit görülmesi istatistiksel olarak anlamlı olmakla birlikte klinik olarak anlamlı bir bulgu olmayabilir. Ayrıca bu çalışmada yapılan regresyon analizinde PİK yerleştirilirken ilk girişimde başarılı olmanın, yaşın ve vücut tarafının birlikte değerlendirildiği modelde sol kola PİK uygulamasının flebit riskini arttırdığ bulundu (Tablo 4). Hastaların aktif olmayan ekstremitesine uygulanan PİK kayanaklı flebitin ekstremite tarafı ve anatomik bölge dışında tedavi kaynaklı, kateter kaynaklı, hemşire kaynaklı birçok farklı karıştırıcı faktörden etkileniyor olması sebebiyle literatürde bu konunun henüz yeterince açığa kavuşmayan tartışmalı bir konu olduğunu düşündürmektedir.

Periferik intravenöz kateter uygulanırken ilk girişimin başarısız olması yani uygulama sırasında PİK'e kan gelmemesi, mayi verilememesi, uygulanan bölgede şişme veya ağrı görülmesi, yeni bir katetere ihtiyaç duyulması başarısı girişim göstergesi olup, hastanın damar yapısının çeşitli nedenlerden ince ve hassas olduğunu ya da uygulamayı yapan hemşirenin bilgi ve deneyiminin yetersiz olduğunu düşündürebilir $(2,36)$. Ayrıca aynı damara PİK uygulaması için yapılan girişim sayısı arttıkça, damarın uğradığı travma, mikroorganizmaların geçişi için uygun bir ortam hazırlanması ve venin intima tabakasının daha fazla hasara uğramasına bağlı olarak flebit riskini de arttırmaktadır (29, 32). Simin ve arkadaşları (2019) iki veya daha fazla başarısız girişimin flebit oluşumunu artırdığını belirtmiştir (1). Çalışmamızda literatürle benzer şekilde birinci denemede başarısız olunan ve aynı ven boyunca tekrarlı girişim yapılan PİK'lerde daha fazla flebit geliştiği saptandı (Tablo 3). Ayrıca bu çalışmada yapılan regresyon analizinde de bu bulguyu destekleyici şekilde ilk girişimin başarısız olmasının flebit riskini yaklaşık 4.5 kat arttırdığını gösterdi (Tablo 4).

Literatürde özellikle hipertonik solüsyonların sürekli infüzyonunun ven duvarında yarattığı mekanik travmayı arttırdığı ve kimyasal flebit gelişimi hızlandırdığı belirtilmektedir $(8,28,31-35)$. Bu çalışmadaki hastalara hipertonik solüsyonların infüzyonu oldukça az olmakla birlikte, sürekli infüzyon yapılan PİK'lerde flebit gelişiminin daha fazla olduğu bulundu (Tablo 3). Uslusoy ve Mete (2008) yaptığı çalışmada hipertonik solüsyonlar flebit riskini geliştirdiğini belirtmiş olup sürekli infüzyonun da flebit gelişimini artırdığını ifade etmiştir (8). Nyika ve arkadaşları (2018) izotonik ve hipertonik solüsyon alan hastalarda flebitin daha sık gözlendiğini belirtmiştir (31). Kan sıvısı osmoloritesi ve izotinik sıvı osmoloritesi birbirine yakın olmakla birlikte uzun süreli sürekli infüzyonda damar duvarında hasara ve mikroorganizmaların geçişine daha uzun süre imkan sağlayabileceğinden flebit oluşumuna neden olabilir (28). Bu durum sürekli infüzyon uygulanan hastaların kateterlerinin hemşireler tarafından sıklıkla geçerli ve güvenilir bir flebit tanılama ölçeği ile değerlendirmesi gerekliliğini ortaya koymaktadır.

$\mathrm{Bu}$ çalışmada flebit gelişimini etkileyen bir diğer faktörün kateterin vende kalış süresi olduğu bulundu (Tablo 3). Yapılan bir çok çalışmada kateterin vende kalış süresinin 72-96 saati aşmasının bakteri kolonizasyonunu arttırması sebebiyle flebit gelişimini de tetiklediğini bildirilirken $(8,27,34)$, son yıllarda yapılan meta analizlerde kateterin 72-96 saat kalış süresi ile flebit oluşumu arasında anlamlı bir ilişkili olmadığını belirtilmektedir $(24,32)$. Her ne kadar bu çalışmada $72-96$ saat kalan kateterlerde daha fazla flebit oluştuğu tespit edilse de son kanıtlar hastanın PİK yerleştirilecek periferik venlerinin birden fazla invaziv deneme ile zor bulunabildiği durumlarda, hemşirelerin uygulama sırasında aseptik tekniklere uyması, venlerin düzenli olarak flebit açısından değerlendirilmesi koşulu ile kateterin 72-96 saatten daha uzun kalmasında sakınca olmadığını bildirmektedir $(24,32,34,35)$. Bununla birlikte bu çalışmada yapılan regresyon analizinde PİK'in vende kalış süresinin ve infüzyonun devam etmesinin birlikte flebit riskini arttırdığı bulundu. Bu bulgu venin kalış süresi uzadıkça ve infüzyon devam ettikçe damar duvarının daha kısa sürede hasara uğradığı ve enfeksiyon oluşma ihtimalini de arttırdığını düşündürmektedir.

$\mathrm{Bu}$ çalışmada uygulanan kateterlerin boyutunun flebit oluşumu üzerine anlamlı bir etkisinin olmadığı bulundu (Tablo 3). Literatürde kalın ve uzun kateterlerin damarda daha fazla travmaya sebep olduğundan flebit oluşumunu arttırdığını savunanlar $(24,26,31)$ bulunmakla birlikte, bu çalışma ile benzer şekilde kateter numarasının flebit oluşumu üzerine etkisinin olmadığını belirten çalışmalara da rastlanmaktadır $(30,33)$. Literatür incelendiğinde uygulanan PİK'lerin venöz yapının üst ekstremitede daha ince ve hassas olması nedeniyle damar çapına uygun olarak, kateter çapı damar çapının \%45'ini geçmeyecek büyüklükte olmasını önermektedir $(28,37,38)$. Bu çalışmada PİK uygulaması sırasında hemşirelerin çoğunlukla damar çapına uygun ölçülerde kateter seçmiş olabileceğini düşündürmektedir. Bu kapsamda hemşirelerin PİK uygulamaları sırasında öncelikle kateter büyüklüğünün, kateterin yerleştirileceği venin uygunluğuna, gönderilecek sıvının kimyasal yapısına ve yoğunluğuna, infüzyonun süresine, uygulamayı gerçekleştirecek hemşirenin deneyim ve tercihlerine göre en uygun şekilde seçilmesi gerektiği değerlendirilmektedir. 


\section{Sonuçların Uygulamada Kullanımı}

Günümüzde hastaneye başvurulan hastalara tanı ve tedavi uygulamaları sırasında PİK uygulaması yerine henüz alternatif bir başka yöntem kullanılmamaktadır. Hastalar için vazgeçilmez olan bu kateterlerin istenmeyen komplikasyonlarının biri olan flebitin de özelikle iç hastalığı kliniğinde yatan ve kronik hastalığı bulunan yaşlı hastalarda görülmesi kaçınılmazdır. Fakat bu çalışmada literatürde diğer bir çok çalışmada da olduğu gibi önerilen PİK kaynaklı flebit insidansının oldukça üzerinde bir sonuç elde edildi. Flebit insidansının belirlenen \%5'in altına indirilmesi için hastaların PİK güvenliğinin takibi ve bakımının sağlanması kaliteli bir hemşirelik bakımının göstergesi olması açısından önemlidir. Periferik intravenöz kateter kaynaklı flebit görülme oranını en aza indirmek, risk faktörlerini tanımlamak, oluştuğunda ise erken dönemde flebiti tanılayarak uygun girişimleri başlatmak amacıyla PİK uygulanan bölgenin geçerli ve güvenilir bir skala kullanılarak düzenli aralıklarla değerlendirilmesi önerilmektedir. Elde edilecek flebit görülme sıklığı, basınç ülseri ve enfeksiyon hızı ile benzer şekilde sağlık kurumlarının kalite göstergelerinden biri olarak değerlendirilebilir.

Bununla birlikte bu çalışmada hastanın ileri yaşı, kronik hastalık varlığı, kateter uygulanırken ilk denemede başarısız olunması, venin tekrarlı kullanımı, infüzyonun sürekli olması ve kateterin vende kalış süresi flebit gelişimi açısından risk faktörü olarak belirlendi. Bu kapsamda hemşireler bakım verdikleri, kronik hastalığı olan yaşlı hastalara PİK uygularken flebit gelişime riskinin daha fazla olduğunu bilmelidir. İntravenöz tedavinin devam etmemesi durumunda PİK'lerin en kısa zamanda çıkarılması ve daha önce PİK takılmış ven boyunca tekrar uygulama yapılmaması önerilmektedir.

Son olarak flebitin önlenmesinde hastadan, kateterden, tedaviden ve hemşirelik bakımından kaynaklanan riskleri en aza indirmeyi hedefleyen yeni klinik çalışmalar yapılması önerilmektedir.

\section{Kisıtlılıklar}

$\mathrm{Bu}$ çalışma bir kamu hastanesinin iç hastalıkları kliniğinde tek merkezli bir çalışma olarak planlanmıştır. Cerrahi kliniklerde ve yoğun bakım üniteleri de dahil edilerek yapılan çok merkezli ve daha büyük örneklem ile yapılan bir çalışma evreni daha iyi temsil edebilirdi. Ayrıca hastaların neredeyse tamamına istem edilen intravenöz tedavi ve sıviların benzer olması sebebiyle hipertonik sıvıların, IV antibiyotik tedavinin ya da diğer irritan ilaçların flebit üzerine etkisi araştırılamadı.

\section{Bilgilendirme}

Bu çalışmada yazarların katkı beyanı: fikir/kavram SB, BT, NT; tasarım SB, BT; denetleme ve danışmanlık; BT, NT; veri toplama ve işleme SB, BT; analiz ve yorum SB, BT, NT; kaynak taraması; SB, BT, NT; makale yazımı SB, BT, NT; eleştirel düşünce SB, BT, NT; araştırmanın bütçesi SB, BT, NT. Araştırmanın uygulamasına başlamadan önce bir üniversitenin sağlık bilimleri enstitüsünden etik kurul izni (20/11/2018 tarihli ve 2018/29 sayılı karar) ve il sağlık müdürlügü aracılığı ile çalışmanın yapıldığı hastaneden gerekli izinler (25/12/2018 tarihli ve 76924598-774.99-E.4082 sayılı karar sayılı karar ) alındı. Yazarlar arasında herhangi bir çıkar çatışması yoktur. Ayrıca sorumlu olduğumuz araştırmada herhangi bir firma ya da kurum ile çıkar ilişkisi bulunmamaktadır. Araştırma ile ilgili herhangi bir projeden ya da firmadan destek alınmamıştır. Araştırmanın bütçesi araştırmacılar tarafından karşılanmıştır. Bu çalışmanın yürütülmesinde herhangi bir kurum ya da kişiden maddi destek alınmamıştır. Yazarlar arasında herhangi bir çıkar çatışması bulunmamaktadır.

\section{Kaynaklar}

1. Simin D, Milutinović D, Turkulov V, Brkić S. Incidence, severity and risk factors of peripheral intravenous cannula induced complications: An observational prospective study. J Clin Nurs 2019;28:1585-1599. Doi: https://doi.org/10.1111/jocn.14760.

2. Kuş B, Büyükyılmaz F. Visual infusion phlebitis assessment scale: Study of independent inter-observer compliance. Florence Nightingale Journal of Nursing 2018;26(3):179-186. Doi: https://doi.org/10.26650/fnjn296258.

3. Osei-Tutu E, Tuoyire D A, Debrah S, Ayetey H. Peripheral intravenous cannulation and phlebitis risk. Post Graduate Medical Journal of Ghana [online]. 2015;4(1):10-18. URL: https://pdfs.semanticscholar.org/f578/93736743908f47eb5c2663d374f3244c2956.pdf. 28.08.2019.

4. Gallant P, Schultz A A. Evaluation of a Visual Infusion Phlebitis Scale for determining appropriate discontinuation of peripheral intravenous catheters. J Infus Nurs 2006;29(6):338-345.

5. Gonza J L, Corral J O, Marti C B. Indwell times, complications and costs of open vs closed safety peripheral intravenous catheters: A randomized study. J Hosp Infect 2014;86(2):117-126. Doi: https://doi.org/10.1016/j.jhin.2013.10.008.

6. Rickard C M, Mccann D, Munnings J, Mcgrail M R. Routine resite of peripheral intravenous devices every 3 days did not reduce complications compared with clinically indicated resite : A randomised controlled trial. BMC Medicine [online]. 2010;8(53):1-10. URL: http://www.biomedcentral.com/1741-7015/8/53. 28.09.2019.

7. Urbanetto J S, May T A. Incidence of phlebitis associated with the use of peripheral IV catheter and following catheter removal. Rev Lat Am de Enfermagem [online]. 2016;24(2746):1-9.URL: https://doi.org/10.1590/1518-8345.0604.2746. 28.09.2019.

8. Uslusoy E, Mete S. Predisposing factors to phlebitis in patients with peripheral intravenous catheters: A descriptive study. J Am Acad Nurse Pract 2008:20(4):172-180. Doi: https://doi.org/10.1111/j.1745-7599.2008.00305.x.

9. Chiu P C, Lee Y H, Hsu H T, Feng Y T, Lu I C, Chiu S L, et al. Establish a perioperative check forum for peripheral intravenous access to prevent the occurrence of phlebitis. Kaohsiung J Med Sci 2015;31(4):215-221. Doi: https://doi.org/10.1016/j.kjms.2015.01.007. 
10. Alexandrou E, Ray-Barruel G, Carr P J, Frost S A, Inwood S, Higgins N, et al. Use of short peripheral intravenous catheters: Characteristics, management, and outcomes worldwide. J Hosp Med 2018;22(30):1-7. Doi: https://doi.org/10.12788/jhm.3039.

11. Milutinović D, Simin D, Zec D. Risk factor for phlebitis: A questionnaire study of nurses' perception. Rev Lat Am Enfermagem 2015;23(4):678-684. Doi: https://doi.org/10.1590/0104-1169.0192.2603.

12. Boyce, B. A., \& Yee, B. H. Incidence and severity of phlebitis in patients receiving peripherally infused amiodarone. Crit Care Nurse 2012;32(4):27-35. Doi: https://doi.org/10.4037/ccn2012139.

13. Mihala G, Ray-Barruel G, Chopra V, Webster J, Wallis M, Marsh N, et al. Phlebitis signs and symptoms with peripheral intravenous catheters: Incidence and correlation study. J Infus Nurs 2018;41(4): $260-263$. Doi: https://doi.org/10.1097/NAN.0000000000000288.

14. Infusion Nurses Society. Infusion nursing standards of practice (The official publication of the Infusion Nurses Society). J Infus Nurs (2006);29(1 Suppl):1-92. Doi: http://www.ncbi.nlm.nih.gov/pubmed/ 16429002.

15. Infusion Nurses Society. Infusion Nursing Standards of Practice. (The official publication of the Infusion Nurses Society). J Infus Nurs 2011;34(1 Suppl): 1-110.

16. Boyd S, Aggarwal I, Davey P, Logan M, Nathwani D. Peripheral intravenous catheters : The road to quality $1 \mathrm{mprovement}$ and safer patient care. J Hosp Infec 2011;77(1):37-41. Doi: http://dx.doi.org/10.1016/j.jhin.2010.09.011.

17. Cicolini G, Simonetti V, Comparcini D, Labeau S, Blot S, Pelusi G, Di Giovanni P. Nurses' Knowledge of evidencebased guidelines on the prevention of peripheral venous catheter-related infections: A multicentre survey. J Clin Nurs 2014;23(17-18):2578-2588. Doi: http://dx.doi.org/10.1111/jocn.12474.

18. Devries, M, Valentine M, Mancos P. Protected clinical indication of peripheral intravenous lines: Successful implementation. J Assoc Vasc Access 2016;21(3):89-92. Doi: http://dx.doi.org/10.1016/j.java.2016.03.001.

19. Braga L M, Parreira P M, Oliveira A S S, Mónico L D S M, Arreguy-Sena C, Henriques M A. Phlebitis and infiltration: Vascular trauma associated with the peripheral venous catheter. Rev Lat Am Enfermagem 2018;26(2): 1-8. Doi: http://dx.doi.org/10.1590/1518-8345.2377.3002.

20. Etemadi S. Investigating role of mechanical and chemical factors in the creation of peripheral vein in flammarion in hospitalization patients in hospital in Zahedan, Iran. Life Sci J 2013;10(1): 379-383.

21. Ruchi S, Agnihotri M, Gupta A, Walia I. Epidemiology of infiltration and phlebitis. Nursing and Midwifery Research Journal [online] 2011;7(1): 22-33. URL: http://medind.nic.in/nad/t11/i1/nadt11i1p22.pdf. 28.09.2019.

22. Erdoğan CB, Denat Y. Periferik intravenöz kateter komplikasyonlarından flebit ve hemşirelik bakımı. J Hum Rhythm [online]. 2016;2(1):6-12. URL: http://dergipark.ulakbim.gov.tr/johr/article/view/5000183221/5000161983. 28.09.2019.

23. Chalmers C, Straub M. Standard principles for preventing and controlling infection. Nurs Standart 2006;20(23): 57-65.

24. Chang WP, Peng YX. Occurrence of phlebitis a systematic review and meta-analysis. Nurs Res 2018;67(3):252-260.

25. Wallis MC, McGrail M, Webster J, Marsh N, Gowardman J, Playford EG, Rickard CM. Risk factors for peripheral intravenous catheter failure: a multivariate analysis of data from a randomized controlled trial. Infect Control Hosp Epidemiol. 2014;35(1):63-8. Doi: http://dx.doi.org/10.1086/674398.

26. Do Rego Furtado, L. C. Incidence and predisposing factors of phlebitis in a surgery department. British Journal of Nursing, 2011;20(14):16-25. Doi: https://doi.org/10.12968/bjon.2011.20.Sup7.S16.

27. Atay S, Sen S, and Cukurlu D. Phlebitis related peripheral venous catheterization and the associated risk factors. Nigerian Journal of Clinical Practice 2018;21(7): 827-831. Doi: http://www.ncbi.nlm.nih.gov/pubmed/29984711.

28. Türk Hastane İnfeksiyonları ve Kontrolü Derneği, Ulusal Damar Erişimi Yönetimi Rehberi (2019). Hastane İnfeksiyonları Dergisi. 2019; 23 (Ek 1): 1-54.

29. Saini R, Agnihotri M, Gupta A, Walia I. Epidemiology of infiltration and phlebitis. Nursing and Midwifery Research Journal 2011; 7(1): 22-33.

30. Buzatto L L, Massa G P, Peterlini M A S, Whitaker I Y. Factors associated with phlebitis in elderly patients with amiodarone intravenous infusion. Acta Paul Enferm 2016;29(3):260-266. Doi: http://dx.doi.org/10.1590/19820194201600037.

31. Nyika, ML, Mukona D, Zvinavashe M. Factors contributing to phlebitis among adult patients admitted in the medicalsurgical units of a central hospital in Harare, Zimbabwe. J Infus Nurs 2018;41(2):96-102.

32. Webster, J., McGrail M, Marsh, N, Wallis, M.C., Ray-Barruel G, Rickard C M. Postinfusion phlebitis: Incidence and risk factors. Nursing Research and Practice 2015;691934:1-3. Doi: http://dx.doi.org/10.1155/2015/691934.

33. Salgueiro-Oliveira A, Parreira P, Veiga P. Incidence of phlebitis in patients with peripheral intravenous catheters: The influence of some risk factors. Aust J Adv Nurs 2012;30(2): 32-39.

34. Paşalığlu K B, Kaya H. Catheter indwell time and phlebitis development during peripheral intravenous catheter administration. Pakistan Journal of Medical Sciences, 2014;30(4):725-730.

35. Mestre Roca G, Berbel Bertolo C, Tortajada Lopez P, Gallemi Samaranch G, Aguilar Ramirez M C, Caylà Buqueras J, et al. Assessing the influence of risk factors on rates and dynamics of peripheral vein phlebitis: An observational cohort study. Med Clin 2012;139(5):185-191. Doi: http://dx.doi.org/10.1016/j.medcli.2011.12.021.

36. Aydın S, Arslan G G. Hemşirelerin periferal intravenöz kateter girişimlerine ilişkin bilgi düzeylerinin incelenmesi. DEUHFED 2018;11(4):290-299. 
37. Sharp R, Cummings M, Fielder A, Mikocka-Walus A, Grech C, Esterman A. The catheter to vein ratio and rates of symptomatic venous thromboembolism in patients with a peripherally inserted central catheter (PICC): a prospective cohort study. Int J Nurs Stud 2015;52:677-85.

38. Chopra V, Ratz D, Kuhn L, Lopus T, Lee A, Krein S. Peripherally inserted central catheter-related deep vein thrombosis: contemporary patterns and predictors. J Thromb Haemost 2014;12:847-54. 